\title{
An Investigation into CALL in English Language Teaching through Language Laboratory
}

\author{
Kazi Dawood Hafiz
}

\begin{abstract}
Whether we like or not, globalization is changing the way we work and live. We are increasingly faced with complexities and to be successful in this environment, we need good communicative skills that can help us make reliable decisions and acquire new knowledge. But what do we mean by good communicative skills? Basically it comes down to one single concept - \'linguistic competence $\backslash$. Since language is an integral part of globalization, competence in one common language, i.e. English, has become even more crucial than before. Thousands of researches have been done on different approaches, methods and their effectiveness in ELT. Language Lab based ELT is not a new concept either. This paper aims at sharing some experiences with the readers and ELT practitioners about the actual effectiveness observed by the author being the instructor $\lambda^{\prime}$ mediator ${ }^{\prime}$ of English language classes in the language lab.
\end{abstract}

Key Words: ELT, CALL, Integrated Skill, ICT.

\section{Introduction}

The modern competitive global work arena expects communicative skills and high English language proficiency as an essential element in the skills required to be a qualified competitor professional. With the view of improving and extending lifelong language and making English language teaching more effective, language lab has become a valuable and obviously challenging trend in the autonomy delegated to higher professional educational institutions. Understanding the scope of CALL is made complicated by the constant advancements in hardware and software and an increase in computer literacy among both teachers and learners. Three decades ago, CALL would have been constrained to on-screen written exercises with simple graphics. Currently, CALL interactions are likely to include sounds, animation, video and communication over local area networks, e-mails and internet chat lines. The present study shows and analyzes the information on the use of Integrated-Skill Instruction in language laboratory to promote English Language Teaching and learning in different private as well as public universities of Bangladesh. It also explores the challenges faced by English teachers incorporating Computer Assisted Language Learning (CALL) approach in their teaching. The results of the study concerning English teachers' and students' reflections and expectations on the use of language lab are presented here. The possible solutions to the emerging problems are stated as well.

\section{Integrated-Skill Instruction}

"Technology cannot be goal in itself. However, a holistic integration of technology in teaching is the need of the hour" - Mini Joseph

Nothing succeeds like success. This phrase goes well with technology which has surpassed everything in its progress. Sophistication in computer technology has made it available as a necessary tool for learning and developing the skills of oral and written interactions, commonly referred to as 'Computer Assisted Language Learning' (CALL). This new learning of language, especially for non-native learners of English as a second language (ESL) and English as a foreign language (EFL) is fast gaining acceptance globally and the results are quite encouraging. The best part is that it is learner centric rather than teacher centric.

Many private and public universities such as Ahsanullah University of Science and Technology or Noakhali Science and Technology University have made use of language lab mandatory for students. The supporters of the view that ICT tools can enhance English language teaching believe that these tools have removed the limitation of time and space found in traditional language teaching. "Integrating ICT tools in teaching can lead to increased students' learning competencies and increase opportunities for communication." (Frayer, 2005) Besides motivating the learners and raising their self-esteem and confidence, ICT can enhance their interaction, verbalization and involvement in collaborative learning. The use of multimedia for language integrates listening, speaking, reading and writing. Learning looks like a tapestry that is woven from many strands like teacher, learner, setting and the relevant language. The skills are also interwoven during instruction. Two types of integrated skill instruction are content-based language instruction and task-based language instruction. The first of these emphasizes learning content through language, while the second stresses doing tasks that require communicative language use. In content-based instruction, students practice all the language skills in a highly integrated and communicative fashion. The Cognitive Academic Language Learning Approach, created by Chamot and O’Malley (1994) shows how language learning strategies can be integrated 
into simultaneous learning of content and language. In task-based approach, tasks are defined as activities that can stand alone as fundamental units and require comprehending, producing, manipulating or interacting in authentic language while attention is principally paid to meaning rather form (Nunan, 1989). Both of these benefit from a diverse range of materials, text-books and technologies for language labs and provide the learners with immediate feedback that facilitates their learning process. The use of text, images, sound/audio aids, visual aids, interactive activities, recording etc. enhances learners' interests in language classes.

\subsection{Language lab: A platform for integrating and developing language skills via CALL}

Language lab provides a platform where teachers can try experiments on themselves and the learners as well. By observing and reflecting on their own problems and failures as learners, English teachers can seek to establish principles, which will help them improve their teaching. The teachers should choose instructional materials, textbooks and technologies that promote the integration of listening, reading, speaking and writing as well as associated skills of syntax, vocabulary and so on. Mere existence of computers in the language lab does not lead to learning. The teachers must lay emphasis on guidance rather than learner-control. A learning atmosphere is to be created. Like any other tools or instruments, the language lab becomes most useful in the hands of a craftsman who knows how to use it skillfully. Hence, the major objectives of the study will be as follows:

$\circ$ To analyze the recurrent situation of ELT through language lab at the tertiary level of education in Bangladesh

- To justify the application of CALL in language labs

- To find out the frequency of using language lab for ELT

- To identify the resources used in the language lab

- To find out the learning activities conducted in language lab

- To discover the expectations of the students from English teachers

○ To identify the challenges faced by the English teachers

\section{Research Tools and Methodology}

The study was conducted on 200 students at 3 universities in Dhaka and Noakhali. A close-ended questionnaire supplied with specification was administered. The respondents were the students from the first or second year of study at the following departments: Pharmacy, Computer Science and Telecommunication Engineering, Applied Chemistry and Chemical Technology, Fisheries and Marine Science (Noakhali Science and Technology University), Electrical \& Electronic Engineering, Industrial \& Production Engineering, Mechanical Engineering (Ahsanullah Science and Technology University) and Bachelor of Business Administration (University of Liberal Arts Bangladesh).

\subsection{Frequency of using language lab}

The question was asked to identify how frequently language lab is used for the purpose of ELT by English teachers in the universities under survey.

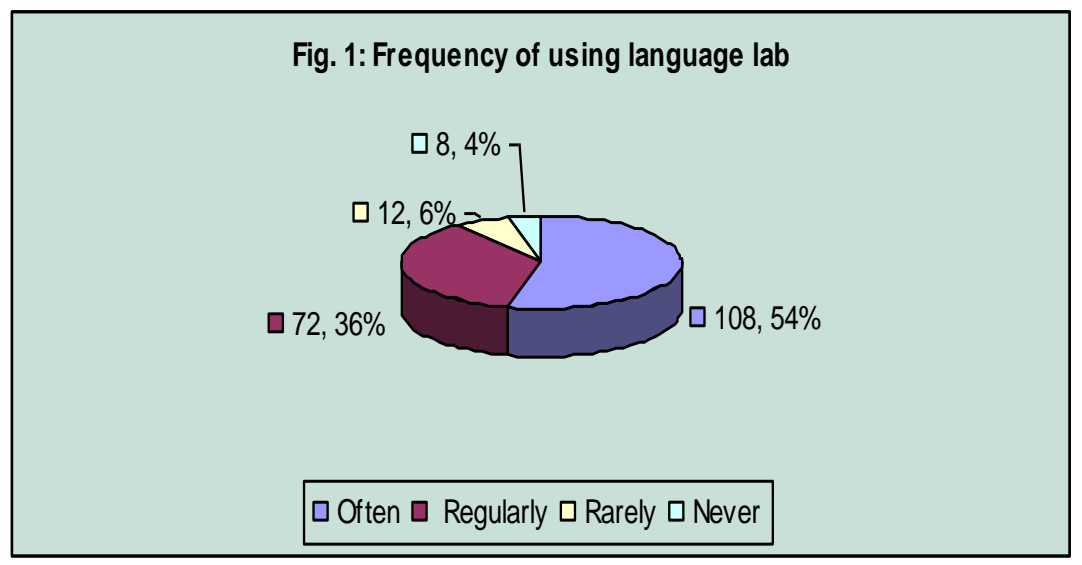

The data demonstrates that the majority $(54 \%)$ of respondents use language lab often, whereas it is used very regularly by $72(36 \%)$ respondents. Few students $(6 \%)$ use lab rarely, only to maintain attendance and performance and rest of them (4\%) do not even bother about those.

\subsection{How often language lab should be used}

The following chart reveals the data collected in the response in the respondents' view of using language lab for teaching purpose. 


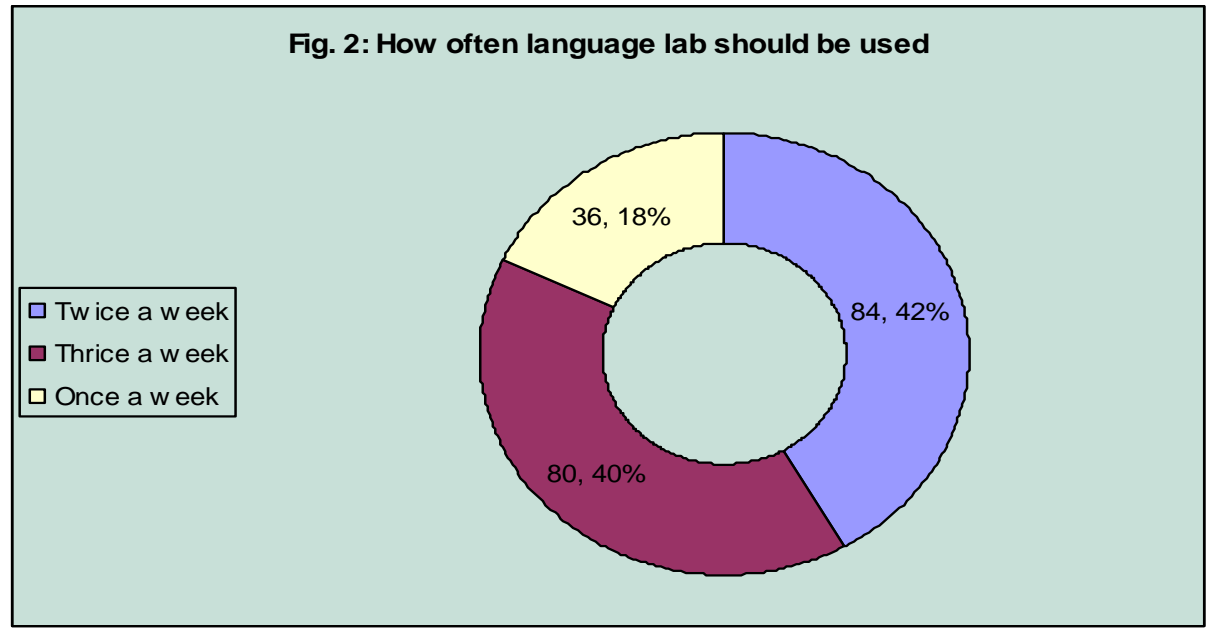

The data illustrates that $42 \%$ of students want at least two labs a week where nearly same percentage (40\%) of students strongly disagree with language learning having one lab a week; they want at least three labs a week for better improvement. Besides, there are few students (18\%) who want one lab a week. Most significantly, there is no one who does not want to use language lab.

\subsection{Resources used in language lab}

The question was asked to find out the resources preferred for ELT in the language labs.

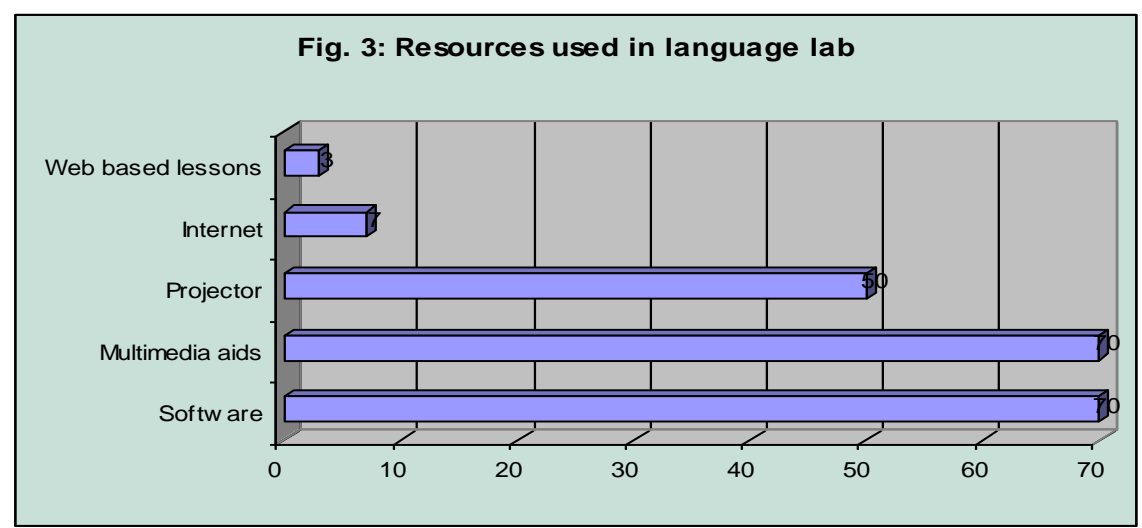

It is evident from the above data that multimedia aids and software are the resources used by majority of the respondents. Projector for watching English movies and video clips is ranked second whereas internet and web based lessons are used by very less percentage of the target students.

\subsection{Learning activities accomplished in language lab}

The following data demonstrates that audio conversations are used more in labs and it is followed by the use of video clippings. A very less number of students are benefited by demonstrations given in the lab.

Fig. 4: Learning activities accomplished in language lab

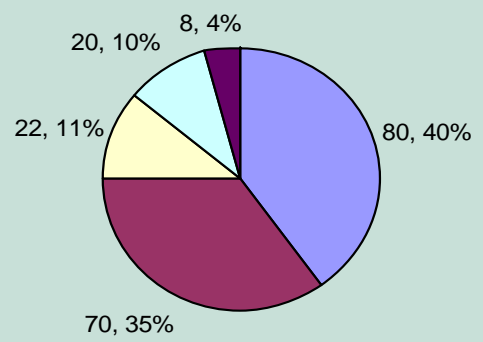

$\square$ Audio conversations $\square$ Video clippings $\square$ Internet $\square$ Demonstrations $\square$ Handouts 


\subsection{Students' expectations from teachers}

The following table is given to illustrate different real-life expectations of the students from their teachers in the lab.

\begin{tabular}{|l|l|l|}
\hline \multicolumn{1}{|c|}{ Activities } & \multicolumn{1}{c|}{ No. of Respondents } & \multicolumn{1}{c|}{ Percentage } \\
\hline Group work/Discussion/Debates/Presentation skills & 96 & $48 \%$ \\
\hline Software based conference/conversation & 48 & $24 \%$ \\
\hline Rectification of errors through drillings & 46 & $23 \%$ \\
\hline Web-based teaching/On line language games & 6 & $3 \%$ \\
\hline Role playing & 4 & $2 \%$ \\
\hline Total & 200 & $100 \%$ \\
\hline
\end{tabular}

The collected data makes it obvious that majority of respondents expect their English teacher to give them more and more professional speaking skill (job interviews, debates, group discussions, oral presentations, real-life conversations etc.). For improving their listening skill many students expect their teachers to use different forms of conversing and conferencing. Others want to get rid of the silly mistakes they suffer from when they use the target language in their real life. Very few students prefer role plays or games. It was reported that these minority portion of the respondents are not very regular in classes either. The survey was done with tertiary level students and their major focus is principally career oriented. They feel the need of practical skill and knowledge in English language and communication through the target language.

\section{Findings at a Glance}

The key findings of the study are as follows:

- The frequency of using language lab among students is satisfactory. Students prefer lab classes to traditional theory classes where their participation hardly exists. The reason might be the new taste they get in the language labs in comparison with the traditional classroom learning in schools and colleges.

- The majority of the students want more than one lab per week for maintaining practice. Practice is the key issue of improving or even mastering any skill.

- Simple demonstrations and handouts are not much liked by the students as well as teachers; whereas audiovisual aids play a vital role in the interactive process of teaching and learning.

- Learners' main target is to know how to use the language in oral and written form correctly. Activities related to professional and academic purpose are mostly expected by the learners from their teachers.

During the survey it was discovered that a good number universities have not yet established language lab. But in the universities where well-equipped labs are available, English teachers are sincere in making use of it for the betterment of the students. In few universities, visited only, labs are not well-maintained due to lack of fund as stated by some teachers. Few teachers actually need formal training for operating labs properly since they did not show much confidence in using it. They pointed out below discussed challenges faced by them while incorporating CALL approach in their teaching:

- Almost all English teachers find the job of designing, editing and modifying the digital materials as tedious and time consuming. As Lee (2001: 43-50) also quotes "Therefore, instructions may resist Internet based activities or projects that require substantially more preparation time."

- The lack of facilities such as audio-visual aids, OHPs and, above all, uninterrupted supply of electricity for providing smooth and convenient environment for teaching and learning is seen as a major limitation.

- Some technical issues upset English teachers to incorporate on-line language teaching. As Singhal (1997) states, "When the network traffic stalls due to many users or some other network glitches, it may take time to access information or browse the internet. Most students may feel discouraged if they have to wait long for web sites to appear. English teachers may also feel frustrated if they are not computer literate to debug computer or internet-related problems in web-enhanced language classes.

- Technophobia due to lack of experience with computers is another reason prevailing in few English language teachers. In the similar context, Towndrow highlighted number negative impacts of computers on education. Some of the doubts are: information overload can lead to techno-stress; computer mediated synchronous communications has generated more text with minimal interactions; learners' disappointment due to lack of immediate feedback; without enough CALL training for English teachers, teaching simply results in learner apathy, disorientation and abuse. (Towndrow, 2002)

- Incredibility of websites is yet another challenge. For example, as narrated by Singhal (1997), searching for necessary websites using search engines like Google or Yahoo is sometimes tiresome. It is obviously true that these search engines have made information very much available but choosing the right websites might ask for sound knowledge about the features a good website should have. Articles found on the internet sometimes lack credibility. In addition, the internet like a reservoir of knowledge offers access to all type of 
issues and topics, some of which are unsuitable for young language learners (Singhal, 1997). There is a lack of unified theoretical framework for designing and evaluating CALL system.

\section{Solutions Proposed}

So far, we have been discussing the different pros and cons of now popular method of teaching English. For understanding the possible solutions and implementing them in our teaching, we must go through the actual concept of CALL, the prerequisites, concepts taken from the experts and its possible implementation.

\subsection{Implementing 'Computer Assisted Language Learning' successfully}

For many years, foreign language teachers have used computer to provide supplemental exercises. In recent years, advancements in computer technology have motivated software developers as well as teachers to reassess the use of computer and consider it as an essential part of daily foreign language learning. Innovative and interactive software programs, authoring capabilities, CD technology and elaborate computer network are providing teachers with new methods of incorporating vocabulary, grammar, interactive sessions on real-life situations and writing into it. At the same time students gain access to audio, visual and textual information about the culture and language of non-native and native speakers. Simultaneously they get necessary information and tips on developing various skills of communication. Once the right kind of technological environment is ensured for language learning in CALL, two options of learning, i.e. (i) self-learning or (ii) integrated group learning are always available.

\subsubsection{Self-learning through the use of technology}

A multimedia computer, good quality headphones and other study materials along with software support are the basic requirements here. Environment must be a quiet one which has no echo. Self-learning has its advantages and limitations too. Developing listening skills and viewing materials to enrich basic vocabulary and grammar, providing perfect environment for self-analysis, providing privacy of learning for beginners are some the advantages of self-learning. On the other hand, lacking natural versatility and originality, changing interest and aim to technology are some of the limitations of self-learning.

\subsubsection{Integrated group learning using language lab in CALL}

State-of-the-art language teaching involves teaching syntax and grammar, phonetics and communication skills besides vocabulary enhancement. The task for the teacher is to motivate the student to speak and to improve his/her oral/aural abilities. Students also need facilities to assess his/her own performance. Multimedia language lab is an invaluable tool in this process. A CALL followed language laboratory should normally have the following features and functions:

- The lab is fully interactive with teacher to learner, learner to teacher and learner to learner interactions.

- Teachers can address all learners at a time or to a specific learner. A learner can individually communicate with the teacher to ask a question or to clarify a doubt. Intra-class communication is done in the target language.

- Learners can take on-line objective type or short answer type tests chosen by the teacher for testing specific deficient areas. They can also exchange messages and use them creatively to supplement oral interactive activities.

- Audio files can be transferred to student terminal for on-line listening. Option like transcribing the audio material to cross check the effectiveness of their listening can also be given.

- Watching English movies and other videos is highly effective for the appropriate use of body language as well as for enhancing oral skills. Apart from using videos from language teaching software and CDs, selfmade video shoots will be a rich source of learning and feedback. This will help learners develop and improve their understanding of pronunciation, stress, intonation, expression etc. Asking them to write a review on the movie they watched is a very good way to fill the loopholes in learners' writing ability.

- Lab can provide the option of speech recognition with in-built pronunciation of some words and a facility to compare the users' voice with the model. Here, the teacher should choose pronunciation program using the RP (Received Pronunciation) as it has gained a global acceptance. However, to be more user specific, teacher-authored programs will be more suitable. Using the programs successfully, students can compare their progress in addition to aural comparison.

- Learners are usually faced with 'extrinsic' motivation and manufacture 'intrinsic' motivation when it suits them. Teachers and learners need to create motivation through establishing goals and understanding how CALL activities can help achieve them. (Beatty, 2003)

- Teachers should minimize the isolation of learners, especially in a row-on-row situation to maximize interactions and opportunities for scaffolded learning. 
- Engaging in CALL should be as painless as taking a book out of a library or using any other common academic resource.

- There is seldom enough time or resources for comprehensively learning a language in a classroom, so learners using CALL should be encouraged to take responsibility for their own learning. This means making the use of computing facilities when they have access to them and finding ways to follow up on what they have learned when they are away from the computer.

- One essential feature is the formation of multiple groups to carry out paired conversations using role plays and group discussions. Group discussion is an essential criterion for selection of jobs, while a role-play develops face to face conversational skills, confidence and fluency. In a group activity, students can discuss a subject with the partners and can reduce inhibitions to speaking. In a paired conversation, a learner can overcome the fear of being spotted. Once the required confidence is gained, group interactions should be carried out separately.

- Learners can be taught to create power point slides with live demos. A teacher can view their monitor screens for effective monitoring of the class.

- Loud reading practice is a tested tool for bringing clarity and fluency in speaking. Reading activities can be recorded in a language laboratory for self-analysis and monitoring the speed of speaking, which should be around 150-160 words per minute.

- Writing skill should also be made an important part of the laboratory activities. Learners may be asked to write passages on eye-catching visual clues, pictures and video clippings transformed or shown to them on their monitor screens. In this way, a multimedia technology of a language lab can be proved to be an excellent additional tool for strengthening the skills of word building, grammar, reading and writing too.

- Above all, language lab sessions remove the tedium of a traditional language learning class.

\subsection{Suggestions for teachers and administrators}

Although it may sound very odd to suggest people especially administrators, the following writings deserve a second thought:

- English teachers must be open to update and adapt to contemporary age of technology. They should incorporate multimedia-printed materials supplemented with electronic means, i.e. audio/video, TV, computer/internet, educational periodicals etc. in daily teaching rather than following traditional teaching.

- Administrators often have mistaken belief that buying hardware by itself will meet the needs of the language lab devoting lion portion of budget to such and ignoring software and training needs. They cut down the number of teaching staff needed and manage fund for infrastructure. This notion should be totally changed.

- The institutes that teachers are working for must offer funds as an incentive to support their English teachers. In absence of this, some teachers may feel not worthwhile to spend much time designing and updating their web-based or self-tailored teaching materials.

- English teachers can be given competency-based well organized specialized prerequisite in-service training in order to provide more audience-targeted instructions in English teaching.

- The management can arrange for learner-training sessions that promote efficient and effective language learning. Learning strategies include bringing about situations through which students can become more aware of their present learning strategies, by comparing them with those of fellow learners.

\section{Conclusion}

With the focus on language, communication and culture, English language teachers are continually searching for better ways of accessing authentic materials that will improve their students' knowledge and skills in the targeted areas. As the technology of internet has transformed communication around the world, it is natural that it should play a major role in a multimedia language laboratory for developing English language skills. BBC is doing an excellent job in providing regular on-line lessons on English language learning. But the crucial factor that leads to the failure of language lab, CALL or any other technology in language education is not the failure of technology, but the failure to invest adequately in growth of a person as a teacher and teacher training. The ignorance of the administrators, management and the human component necessary to make a language laboratory also add to this failure. At the same time, the teachers have to make learners understand that their aim is not mastering technology but the language itself. However, language lab should not replace the classical method of language teaching. It supplements the basic training.

\section{Acknowledgements}

When I was only a new instructor in English language classes, I always tried to share my experience in classroom with other colleagues of mine. They guided me by their experience. Few years ago, Professor Dr. Rubina Khan gave me an assignment of identifying the challenges in integrated skill development in English language classes. Students and instructors who were an integral part of this case study helped me a lot. Special thanks to Ms. Ruhul Asfia who had been another inspiration as a colleague at Primeasia University and to AUST for support. 


\section{References:}

[1] Beatty, K. (2003) Applied Linguistics in Action: CALL. London: Pearson.

[2] Chamot, A. U., \& O’Malley, J. M. (1994) The CALLA handbook: Implementing the cognitive academic language learning approach. Reading, MA: Addison Wesley.

[3] Frayer, D. (2005) "Creating a New World of Learning Possibilities through Instructional Technology". AAHETLTR Information Technology Conference. 1997. Colleges of Worcester Consortium.

[4] Lee, Johnny. (2001)“The Internet for English Language Teaching”. The Reading Matrix 1.2: 43-50.

[5] Nunan, D. (1989) Designing Tasks for the Communicative Classroom. Cambridge, UK: Cambridge University Press.

[6] Rajput, Kavita Singh \& V. K Jain (2011) "Effective ELT via Language Lab: A Survey of Engineering Colleges". Literary Discourses 2.1: 219-227.

[7] Singhal, M. (1997) “The Internet and Foreign Language Education: Benefits and Challenges". The Internet TESL Journal 3.6: Retrieved February 18, 2005 from <http://iteslj.org/Articles/Singhal-Internet.html>

[8] Towndrow, P. A. and M. Vallace. (2002) Using Information Technology in the Language Classroom. Singapore: Prentice Hall. 